\title{
Biossegurança e risco ocupacional entre os profissionais do segmento de beleza e estética: revisão integrativa
}

\author{
Biosafety and occupational risk among beauty and esthetics professionals: an integrative review
}

Bioseguridad y riesgo ocupacional entre profesionales del segmento de belleza y estética: revisión integrativa

Juliana Ladeira Garbaccio ${ }^{1}$, Adriana Cristina de Oliveira²

\section{RESUMO}

Atividades realizadas nos estabelecimentos de estética e beleza favorecem a transmissão de micro-organismos e de doenças como hepatite B e C. Objetivou-se identificar com este estudo a produção científica mundial em relação ao conhecimento e adesão às recomendações de biossegurança entre profissionais do segmento da estética e beleza, os riscos biológicos a que estão expostos profissionais/clientes. Realizou-se revisão integrativa da literatura nas bases da Biblioteca Virtual em Saúde, Science Direct e SCOPUS, sem delimitação temporal. Foram selecionadas dezessete publicações relacionadas às profissões de manicures/pedicures e barbeiro. O desconhecimento sobre biossegurança em relação ao descarte de perfurocortantes, condutas após acidentes com material biológico, mecanismos de transmissão microbiana e reprocessamento de materiais foi verificado. Destacou-se baixa adesão dos profissionais ao uso de equipamentos de proteção individual, à lavagem de mãos e à proteção vacinal. Espera-se que tais achados possam subsidiar reflexões sobre práticas seguras neste segmento, voltadas para profissionais e clientes.

Descritores: Centros de Embelezamento e Estética; Podiatria; Exposição a Agentes Biológicos; Precauções Universais; Enfermagem do Trabalho.

\section{ABSTRACT}

Activities performed in beauty/esthetic establishments favor the transmission of microorganisms and diseases such as Hepatitis B and $\mathrm{C}$. This study aimed at identifying the global scientific production regarding the knowledge of and adherence to biosafety recommendations among professionals of the beauty and esthetics industry, as well as the biological risks to which clients/workers are exposed. An integrative review was performed utilizing the Virtual Health Library, Science Direct and SCOPUS databases, with no time delimitation. Seventeen publications related to manicure/pedicure and barber professions were selected. Lack of knowledge regarding biosafety in terms of how to dispose of sharp instruments, procedures to follow after an accident with biological material, microbial transmission mechanisms and reprocessing of materials was observed. Highlights included the low adherence of workers to using individual protective equipment, hand washing and protective vaccination. We hope the findings will promote critical thinking regarding safe practices, aimed at workers and clients alike.

Descriptors: Beauty and Aesthetics Centers; Podiatry; Exposure to Biological Agents; Universal Precautions; Occupational Health Nursing.

\section{RESUMEN}

Las actividades realizadas en establecimientos de estética y belleza favorecen la transmisión de microorganismos y enfermedades como hepatitis B y C. Se objetivó identificar la producción científica mundial relativa al conocimiento y adhesión a las recomendaciones de bioseguridad entre profesionales de estética y belleza, y los riesgos biológicos que amenazan a clientes y profesionales. Se efectuó revisión integrativa de literatura en bases Biblioteca Virtual en Salud, Science Direct y SCOPUS, sin delimitación temporal. Fueron seleccionadas 17 publicaciones relativas a las profesiones de manicura/pedicura y barbero. Se verificó desconocimiento sobre bioseguridad relativa al descarte de punzocortantes, conductas posteriores a accidentes con material biológico, mecanismos de transmisión microbiana y reprocesamiento de materiales. Se destacó la baja adhesión profesional a utilizar equipamientos de protección individual, al lavado de manos y a la vacunación. Se espera que estos hallazgos ayuden a reflexionar acerca de prácticas seguras en el segmento, orientadas a profesionales y clientes.

Descriptores: Centros de Belleza y Estética; Podiatría; Exposición a Agentes Biológicos; Precauciones Universales; Enfermería del Trabajo.

\footnotetext{
1 Enfermeira e Odontóloga, Mestre em Microbiologia. Discente do Programa de Pós-Graduação em Enfermagem, nível Doutorado, da Escola de Enfermagem da Universidade Federal de Minas Gerais (EE/UFMG). Belo Horizonte, MG, Brasil. E-mail:julade@gmail.com.

${ }^{2}$ Enfermeira, Doutora em Enfermagem. Professora Adjunta da EE/UFMG. Belo Horizonte, MG, Brasil. E-mail: adrianacoliveira@gmail.com.
} 


\section{INTRODUÇÃO}

Os estabelecimentos que prestam serviços na área de beleza e estética, definidos na Classificação Nacional de Atividades Econômicas do Instituto Brasileiro de Geografia e Estatística (CNAE-2.0-IBGE), como serviços de cabeleireiros e Outras Atividades de Tratamento de Beleza fazem parte do cenário atual e contam com um grande número de consumidores. As ocupações profissionais desse segmento compreendem cabeleireiros, manicures, barbeiros, massagistas, esteticistas, pedicures, calistas, trabalhadores de clínicas de estética, institutos de beleza, tratamento capilar e depilação(1).

Alguns fatores provocaram a expansão destes serviços no Brasil a partir da década de 1990, como a crescente inserção da mulher no mercado de trabalho e - maior acesso aos meios de comunicação, que trouxeram padrões de imagem alimentados pela mídia. O resultado foi a sofisticação deste mercado que é empregador de expressiva mão-de-obra não necessariamente qualificada dada a facilidade de se ingressar no ramo. Não se exige investimento financeiro considerável nem comprovação da capacitação técnica.

Uma das características da atividade de estética corporal que vem chamando a atenção cada vez mais dos pesquisadores, se deve ao contato direto e a manipulação de micro organismos que podem se comportar como agentes potencialmente infecciosos. Assim, o ambiente e as atividades realizadas nos salões de beleza e estética são propícios para a transmissão de micro organismos, seja por contato direto ou indireto, em conseqüência, normalmente, da precariedade de infraestrutura e despreparo técnico dos recursos humanos. Esse despreparo é consequência quase sempre da baixa formação escolar e profissional, além do desconhecimento de noções básicas sobre doenças passíveis de transmissão por contato com micro organismos e nos constantes desequilíbrios da tríade: agente, hospedeiro e meio ambiente $\mathrm{e}^{(1-3)}$.

Ante o exposto, o presente estudo se justifica pela relevância e atualidade da temática. Além disso, verificase uma escassez de estudos direcionados à adesão e conhecimento dos profissionais do segmento da estética e beleza quanto às recomendações de biossegurança, ao contrário da vasta literatura na área da saúde ${ }^{(3)}$.
Diante deste contexto este estudo tem como questão norteadora a seguinte proposição: identificar a produção científica mundial em relação ao conhecimento e a adesão às recomendações de biossegurança entre os profissionais do segmento da estética e beleza e os riscos biológicos a que estão expostos profissionais e clientes. A partir dos achados desta revisão espera-se fornecer subsídios que auxiliem reflexões sobre práticas seguras na área de beleza e estética para profissionais e clientes.

\section{MÉTODOS}

Tratou-se de uma revisão integrativa da literatura com referencial metodológico à prática baseada em evidências, com base no trabalho do epidemiologista Archie Cochrane, caracterizando-se por uma abordagem voltada ao cuidado clínico e ao ensino fundamentado no conhecimento e na qualidade da evidência. Com o tema e questão norteadora definidos foi realizado o levantamento de artigos científicos, em fevereiro e março de 2011, em periódicos na língua portuguesa, inglesa, espanhola por meio das bibliotecas: BVS (Biblioteca Virtual de Saúde) e Biblioteca Cochrane disponibilizadas pelo Portal Capes acessados no âmbito da universidade. As bases de dados acessadas foram: Lilacs (Literatura Latino americana e do Caribe em Ciências da Saúde), PubMed, Science Direct, CINAHL e Scopus.

Para a busca, não houve delimitação temporal das publicações, uma vez que se trata de um assunto, até então, pouco estudado. Utilizaram-se os descritores padronizados para as ciências da saúde (www.decs.bvs.br) nos idiomas português, inglês e espanhol: Centros de Embelezamento e Estética, Podiatria, Exposição a Agentes Biológicos, Precauções Universais.

Os descritores foram usados isoladamente para avaliar o poder de representatividade do termo no assunto. Observou-se maior quantidade de trabalhos vinculados aos descritores exposição a agentes biológicos (259.757), precauções universais (20.436), podiatria (12.083), centro de embelezamento e estética (214).

Рara a seleção das publicações definiu-se como critério de inclusão serem artigos originais relacionados ao conhecimento e adesão às medidas de biossegurança, 
ao risco biológico ocupacional e aos clientes nos serviços prestados por manicures, pedicures, podólogos, cabeleireiros e barbeiros, relacionados à adesão ao uso de equipamentos de proteção individual (EPI), aos aspectos dos processos de reaproveitamento e descarte de materiais, à situação vacinal dos profissionais e à disseminação microbiana pelas práticas nos estabelecimentos de beleza e estética.

Foram feitas associações entre os descritores sendo obtidos 27 trabalhos considerando inicialmente o título. Após a leitura dos resumos, 25 destes atenderam aos critérios de inclusão. Porém, duas publicações ainda foram excluídas por serem carta ao editor e por utilizar referências já selecionadas para esta revisão, três por tratarem do segmento de tatuagem e "piercing", uma por abordar riscos ocupacionais não biológicos, outra por ser uma tese com artigo original já publicado e uma última por tratar de aspectos jurídicos. Assim mediante os critérios adotados 17 foram analisadas.

A análise criteriosa dos artigos envolveu a classificação hierárquica das evidências, para a avaliação de pesquisas baseada na categorização da Agency for Healthcare Research and Quality (AHRQ) dos EUA, baseada em seis níveis: nível 1- metanálise de múltiplos estudos controlados; nível 2- estudo individual com desenho experimental; nível 3- estudo com desenho quase-experimental, séries temporais ou caso-controle; nível 4- pesquisa descritiva correlacional e qualitativa ou estudos de caso; nível 5- evidências provenientes de relatos de caso ou de experiência; nível 6- opinião de autoridades respeitáveis baseada na competência clínica ou opinião de comitês(4).

\section{RESULTADOS}

Os 17 artigos analisados foram obtidos nas bases Lilacs (4/17), PubMed (7/17), Science Direct (2/17) e CINAHL (4/17). Os profissionais participantes nos estudos foram $47 \%$ manicures e pedicures (8/17), $6 \%$ podólogos (1/17), 24\% cabeleireiros (4/17) e $35 \%$ barbeiros (6/17). Os locais onde as investigações se passaram foram salões de beleza (10/17- 59\%), barbearias (3/17- 18\%), um hospital (1/17- 6\%), uma instituição para idosos (1/17- 6\%) e em serviço de saúde (2/17- 11\%). Quanto à distribuição geográfica das pesquisas seis foram realizados na Europa (35\%), quatro na América do Norte $(23,5 \%)$, três na África (18\%), três na América do Sul $(17,6 \%)$ e um na Ásia (5,8\%). Quanto ao delineamento, trataram-se de seis artigos de prevalência $(35,3 \%)$, dois estudos de caso $(11,7 \%)$, nove descritivos (53\%).

A respeito da formação escolar dos profissionais, cinco artigos (29\%) avaliaram tal característica em manicures/pedicures (1/17), cabeleireiros (1/17) e barbeiros (3/17), observando-se baixo nível educacional e pouca capacitação técnica. O analfabetismo variou entre $2,2 \%$ e $12 \%$, o nível básico de escolaridade variou entre $12,3 \%$ e $56,7 \%$ e a capacitação técnica dos profissionais para a atividade exercida foi de $19 \%$ e $40 \%(2,5-8)$.

Quanto às recomendações de biossegurança, basicamente os estudos analisados tiveram como objetivo avaliar e descrever aspectos relacionados à baixa adesão e o pouco conhecimento dos profissionais evidenciados por: insuficiente quantidade de instrumentais para o atendimento dos clientes, o reuso de materiais descartáveis como as lâminas, a inadequada desinfecção e esterilização de instrumentais e equipamentos, o uso incorreto de soluções químicas desinfetantes, a inadequada assistência no pós trauma à pele e mucosas, o baixo índice de imunização contra o vírus de hepatite $B$ (VHB) e desconhecimento da necessidade de vacinar, o incorreto descarte de materiais cortantes e perfurantes, o uso incorreto ou o não uso de equipamentos de proteção individual (EPI) e as falhas na prevenção de acidentes associado a más condições físicas e sanitárias dos locais(1-3,5-16).

Apenas 24\% (4/17) dos artigos avaliaram ou citaram de alguma forma a ação dos órgãos de saúde ou de vigilância sanitária no apoio aos estabelecimentos ${ }^{(1,5,8,10)}$. Apesar de não ser o foco principal deste trabalho investigar a normatização sanitária para o funcionamento dos estabelecimentos de beleza e estética, sabe-se que ela tem influência na biossegurança e consequentemente na saúde do trabalhador e dos clientes. Além disso, os órgãos sanitários têm um papel não apenas punitivo, mas principalmente educativo.

As publicações em 88\% (15/17) descreveram alguma injúria sofrida por clientes a partir de alguma intervenção por profissionais da beleza e estética ${ }^{(1-3,5-9,11-}$ 17). Quatro delas (23\%) relataram a conduta dos profissionais após causarem lesões com exposição sanguínea sendo que, o mais comum, foi a realização de 
hemostasia química ou mecânica por pressão no local com pedaço de algodão, com toalha ou pela própria digital do profissional desprovido de luvas ${ }^{(1-3,8)}$.

Seis artigos retrataram detalhadamente as lesões de clientes causadas por manicure/pedicure, cabeleireiro e barbeiro pelo diagnóstico de doenças bacterianas (4/17), virais $(1 / 17)$ e fúngicas (1/17) - furunculoses, abscessos nas pernas, nádegas e virilhas pelo Staphylococcus aureus, Staphylococcus aureus resistente à Meticilina (MRSA), Mycobacterium fortuitum, hepatite B e micoses de couro cabeludo (Tinea Capitis) por Microsporum canis $(9,12-13,15-17)$

Houve também registro no ambiente de trabalho destes profissionais a recuperação de Streptococcus $s p$, Pseudomonas sp e Clostridium tetanni nas superfícies de mobiliários de salões de beleza e em instrumentais e de Enterobactérias em alicates, lâminas, espátulas, tesouras, além de agentes biológicos causadores de escabiose e pediculoses, indicando más práticas de higiene e limpeza ${ }^{(10,18)}$.

No que se refere aos vírus, a literatura enfatiza a possibilidade de transmissão dos Vírus da Imunodeficiência Humana (HIV), os vírus de hepatite $B$ (VHB) e C (VHC) $)^{(1-2,5-8,11,15)}$. As hepatites B e C foram consideradas como infecção de risco ocupacional aos barbeiros, cabeleireiros e manicures/pedicures em países como Itália, Turquia e Brasil. As prováveis fontes de infecção apontadas foram as injúrias à pele atingindo o leito vascular através de lâminas, alicates para remoção do eponíquio (cutícula), palitos e tesouras.

Dois artigos (2/17), os únicos publicados com dados do Brasil, ressaltaram que o brasileiro tem o hábito de remover o eponíquio ou cutícula, não ocorrendo em outros países do mundo ${ }^{(1-2)}$. Prática esta que potencializa a possibilidade do contato com sangue, por pequenos cortes causados pelos alicates ${ }^{(1-3)}$. No tocante a sorologia dos profissionais nos mesmos estudos realizados no Brasil, verificou-se a positividade sorológica para VHB e VHC em $10 \%$ das manicures e pedicures avaliadas, sendo $8 \%$ para hepatite B (anti-HBc total) e $2 \%$ para hepatite C (anti-VHC) ${ }^{(1)}$. Na Turquia a prevalência estimada para hepatite B foi de $39,8 \%$ e hepatite C foi $2,8 \%$ entre barbeiros ${ }^{(11)}$.

Um ponto preocupante e, que aumenta o risco de exposição e de contágio dos profissionais ao HIV, VHB e VHC, é o desconhecimento sobre os mecanismos de transmissão destas doenças e das medidas de prevenção adequadas, além da baixa adesão a vacinação contra o VHB. Tais percepções foram descritas em 59\% (10/17) dos artigos avaliados ${ }^{(1-3,5-8,10-11,14)}$. Durante as entrevistas destes estudos verificou-se que os profissionais abordados não acreditavam que podiam ser agente na transmissão dos micro organismos e que o sangramento que eles "às vezes" causavam não seria importante. Alguns não sabiam da possível transmissão de doenças pelo sangue. A baixa prevenção foi denotada pelo não uso de EPI, incorreto descarte de perfurocortante, condutas incorretas após acidente e, não esterilização

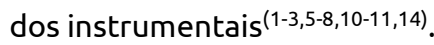

Outra questão observada foi a possibilidade da disseminação microbiana ocorrer devido à reutilização indiscriminada de materiais de uso único, como lâminas, palitos lixas de unha e pela não esterilização ou desinfecção de instrumentais, como alicates, tesouras, bacias dentre outros.

Dos artigos analisados $41 \%$ (7/17) abordaram o reprocessamento de instrumentais e materiais sob a ótica da escolha do método e da técnica empregada, sendo observada baixa utilização da autoclave, o uso de estufas com temperaturas próximas a $100^{\circ} \mathrm{C}$ e tempo de exposição não padronizada além da flambagem para as extremidades dos instrumentais. Substâncias químicas também foram registradas de forma diversificada com produtos como o álcool 90-99\%, querosene, líquido de Javel e, em concentrações não padronizadas(1-3,6-8,15).

Surpreendentemente, verificou-se que a forma pela qual os profissionais se fundamentavam para o uso de tais produtos químicos, se dava pelas informações e orientações recebidas de vendedores e não de forma técnica, sistemática ou mediante as recomendações de órgãos de vigilância sanitária(3).

Além disso, chamou muito a atenção o fato evidenciado em seis artigos que registraram que os profissionais entrevistados não utilizam qualquer método de reprocessamento dos instrumentais $(17,5$ a $49 \%$ de profissionais) e, sobretudo, desconheciam o conceito de esterilização e desinfecção, não diferenciando assim os critérios para a indicação de qualquer um destes processos ${ }^{(1,3,6-8,15)}$.

Sobre o descarte de materiais contaminados como luvas, algodão com sangue e dispositivos perfurocortantes (lâminas, palitos), apenas 12\% (2/17) 
dos artigos analisados enfatizaram este aspecto ${ }^{(3,5)}$. Assim o descarte destes materiais foi relacionado ao lixo comum sem qualquer segregação e proteção em comparação aos demais tipos de resíduos. E apenas 2,7\% dos profissionais relataram 0 descarte de perfurocortantes em caixas próprias ${ }^{(3,5)}$.

O uso de EPI e a adesão à lavagem de mãos, definidas como medidas de precaução padrão foram também negligenciadas pelos profissionais do setor da beleza e estética. O uso de luvas, máscara e a prática de lavagem de mãos foram levantadas em 35\% dos artigos $(6 / 17)$ e todos avaliaram como baixa adesão(1-7). A adesão ao uso de avental ou uniformes por barbeiros e cabeleireiros foi considerado baixo e, ainda não eram regularmente trocados ou lavados, assim como toalhas de tecidos utilizadas durante o preparo das unhas dos clientes $^{(5,7)}$. Destacaram-se em três artigos (3/17) as inadequações sanitárias dos estabelecimentos de beleza e barbearias, como insuficiente espaço físico, falta de água corrente, falta de banheiros e pias para lavagem de mãos, com risco iminente de disseminação microbiana, inclusive a intestinal $(2,5,10)$.

Estes resultados também trazem à tona a possibilidade de que tais inadequações encontradas possam configurar em impactos não só no ambiente dos salões de beleza e estética, mas em outros locais onde estes profissionais prestam seus serviços como em domicílios, hospitais e instituições de longa permanência para idosos (ILPI), dentre outros. Exemplo destas proposições podem ser fundamentadas, como os resultados de estudos acerca da disseminação intrahospitalar de MRSA pela ação profissional de cabeleireiro, e da transmissão de hepatite $B$ para idosos de uma ILPI ${ }^{(12,15)}$. As informações dos artigos de forma sinóptica encontram-se no Quadro 1. 
Quadro 1: Publicações associadas à biossegurança, risco ocupacional e aos clientes do segmento de beleza e estética, 1998-2010.

\begin{tabular}{|c|c|c|c|c|}
\hline Autores/ano/ país & Delineamento/profissionais & Objetivos & Principais resultados & $\begin{array}{c}\text { Nível } \\
\text { evidência }\end{array}$ \\
\hline $\begin{array}{l}\text { Gir; Gessolo, 1998, } \\
\text { Brasil }\end{array}$ & $\begin{array}{l}\text { - Descritivo } \\
-40 \text { manicures }\end{array}$ & $\begin{array}{l}\text { - avaliar conhecimento de manicures sobre biossegurança } \\
\text { após o advento da Aids. }\end{array}$ & $\begin{array}{l}\text {-conhecimento insuficiente sobre a Aids e meios de esterilização } \\
\text { incorretos. }\end{array}$ & IV \\
\hline $\begin{array}{l}\text { Johnson et al, 2001, } \\
\text { Canadá }\end{array}$ & $\begin{array}{c}\text { - Descritivo } \\
-72 \text { manicures e pedicures }\end{array}$ & $\begin{array}{c}\text { - descrever práticas de biossegurança adotada pelos } \\
\text { profissionais. }\end{array}$ & $\begin{array}{l}\text { - baixa imunização pelos profissionais, reuso de artigos, baixa adesão } \\
\text { aos EPI. }\end{array}$ & IV \\
\hline $\begin{array}{l}\text { Takwale et al, 2001, } \\
\text { Reino Unido }\end{array}$ & $\begin{array}{c}\text { - Estudo de caso } \\
\text { - cabeleireiro } \\
\end{array}$ & - descrever dois casos de Tinea capitis. & - infecção adquirida após visita ao mesmo cabeleireiro & V \\
\hline $\begin{array}{l}\text { Ruddy; Cummins; } \\
\text { Drabu, 2001, Reino } \\
\text { Unido }\end{array}$ & $\begin{array}{l}\text { - Descritivo } \\
\text { - cabeleireiro }\end{array}$ & $\begin{array}{l}\text { - determinar o cabelo e artigos de cabeleireiros como fonte } \\
\text { de MRSA. }\end{array}$ & $\begin{array}{l}\text { - isolamento de MRSA em artigos usados por cabeleireiros em } \\
\text { hospital. }\end{array}$ & IV \\
\hline $\begin{array}{l}\text { Candan et al, 2002, } \\
\text { Turquia }\end{array}$ & $\begin{array}{l}\text { - Caso controle } \\
-176 \text { barbeiros } \\
-180 \text { controles } \\
\end{array}$ & - determinar a prevalência de VHB e VHC em barbeiros. & $\begin{array}{c}\text { - alta prevalência de VHB }(39,8 \%) \text { e VHC }(2,8 \%) \text { a maioria sofreu } \\
\text { acidente perfurocortante. }\end{array}$ & III \\
\hline $\begin{array}{l}\text { Winthrop et al, } \\
\text { 2002, EUA }\end{array}$ & $\begin{array}{c}\text { - Caso controle } \\
\text { - pedicures } \\
\text { - } 48 \text { pacientes e } 56 \text { controles }\end{array}$ & $\begin{array}{l}\text { - identificar e investigar a disseminação de furunculose por } \\
\text { Mycobacterium fortuitum entre clientes de pedicures. }\end{array}$ & $\begin{array}{l}\text { - } 110 \text { clientes apresentaram furunculose, houve imersão de membros } \\
\text { inferiores em bacias após depilação. }\end{array}$ & III \\
\hline $\begin{array}{l}\text { Mariano et al, 2004, } \\
\text { Itália }\end{array}$ & $\begin{array}{c}\text { - Caso controle } \\
\text { - manicures, pedicures, } \\
\text { barbeiros, tatuadores } \\
\text { - } 3562 \text { casos e } 7221 \text { controles }\end{array}$ & $\begin{array}{l}\text { - avaliar o papel dos serviços de beleza na disseminação de } \\
\text { VHB e VHC. }\end{array}$ & $\begin{array}{c}\text { - aproximadamente } 15 \% \text { VHB e } 11,5 \% \text { de VHC devido a serviços de } \\
\text { beleza. }\end{array}$ & III \\
\hline $\begin{array}{l}\text { Adeleye; Osidire, } \\
\text { 2004, Nigeria }\end{array}$ & $\begin{array}{l}\text { - Descritivo } \\
\text { - pedicures } \\
\end{array}$ & $\begin{array}{l}\text {-isolar e caracterizar microrganismos de artigos de } \\
\text { pedicures. }\end{array}$ & $\begin{array}{l}\text { - oito espécies bacterianas e cinco fúngicas forma isoladas, algumas } \\
\text { patogênicas. }\end{array}$ & IV \\
\hline $\begin{array}{l}\text { Zahraoui-mehadji et } \\
\text { al, 2004, Marrocos }\end{array}$ & $\begin{array}{l}\text { - Descritivo } \\
-150 \text { barbeiros }\end{array}$ & $\begin{array}{l}\text { - estudar conhecimento de barbeiros acerca do } \\
\text { o risco biológico associado à exposição sanguínea. } \\
\end{array}$ & $\begin{array}{l}\text { - o conhecimento a respeito do risco biológico ocupacional foi } \\
\text { insuficiente, maioria não vacinados. }\end{array}$ & IV \\
\hline $\begin{array}{l}\text { De Schrijver, 2005, } \\
\text { Bélgica }\end{array}$ & $\begin{array}{c}\text { - Transversal } \\
\text { - podólogo, cabeleireiro }\end{array}$ & $\begin{array}{l}\text { - identificar fatores relacionados a óbito por hepatite B } \\
\text { fulminante em instituição de idosos. }\end{array}$ & $\begin{array}{c}\text { - reuso de lâminas por cabeleireiro, podólogos e ausência de } \\
\text { esterilização ou desinfecção de artigos }\end{array}$ & III \\
\hline $\begin{array}{l}\text { Redbord et al, 2006, } \\
\text { EUA }\end{array}$ & $\begin{array}{c}\text { - Estudo de caso } \\
\text { - pedicure } \\
\end{array}$ & $\begin{array}{c}\text {-descrever casos de furunculose em membros inferiores em } \\
\text { pessoas submetidas a atendimento de pedicures. }\end{array}$ & $\begin{array}{l}\text { - os pacientes haviam depilado a perna previamente ao atendimento } \\
\text { de pedicure, com imersão em bacias. }\end{array}$ & V \\
\hline $\begin{array}{l}\text { Corrales et al, 2007, } \\
\text { Colômbia }\end{array}$ & $\begin{array}{c}\text { - Descritivo } \\
-13 \text { salões de beleza }\end{array}$ & $\begin{array}{c}\text {-verificar o emprego dos protocolos de biossegurança } \\
\text { determinados }\end{array}$ & $\begin{array}{l}\text { - presença de artigos contaminados, baixa adesão às determinações } \\
\text { legais de biossegurança. }\end{array}$ & IV \\
\hline $\begin{array}{l}\text { Wazir et al, 2008, } \\
\text { Paquistão }\end{array}$ & $\begin{array}{l}\text { - Descritivo } \\
\text { - barbeiros }\end{array}$ & $\begin{array}{c}\text {-avaliar o conhecimento de barbeiros acerca dos riscos } \\
\text { ocupacionais e identificar práticas passíveis de transmissão } \\
\text { microbiana. }\end{array}$ & $\begin{array}{l}\text { - o conhecimento do risco biológico foi insuficiente, havendo baixa } \\
\text { adesão à higienização de mãos, métodos de reprocessamento de } \\
\text { artigos e EPI. }\end{array}$ & IV \\
\hline $\begin{array}{l}\text { Huijsdens et al, } \\
\text { 2008, EUA }\end{array}$ & $\begin{array}{l}\text { - Descritivo } \\
\text { - esteticista } \\
\end{array}$ & - identificar casos de MRSA em salões de beleza. & - a disseminação de MRSA atingiu profissionais e clientes. & IV \\
\hline $\begin{array}{l}\text { Amodio et al, 2009, } \\
\text { Itália }\end{array}$ & $\begin{array}{l}\text { - Transversal } \\
-105 \text { cabeleireiros }\end{array}$ & $\begin{array}{l}\text { - avaliar o conhecimento, o comportamento frente ao risco } \\
\text { ocupacional para hepatite B, C e HIV }\end{array}$ & $\begin{array}{l}\text { - profissionais conheciam mecanismo de transmissão microbiana, } \\
\text { usavam métodos de reprocessamento e EPI incorretamente. }\end{array}$ & III \\
\hline $\begin{array}{l}\text { Arulogun; Adesoro, } \\
\text { 2009, Nigeria }\end{array}$ & $\begin{array}{l}\text { - Descritivo } \\
\text { - } 45 \text { barbeiros } \\
\end{array}$ & - avaliar as medidas de precaução padrão entre barbeiros. & $\begin{array}{l}\text { - reprocessamento incorreto, ocorrência de acidentes } \\
\text { perfurocortante e condutas profiláticas inadequadas. }\end{array}$ & IV \\
\hline $\begin{array}{l}\text { Oliveira; Focaccia, } \\
\text { 2010, Brasil }\end{array}$ & - 100 manicures e pedicures & $\begin{array}{c}\text { - verificar o uso das recomendações de biossegurança, o } \\
\text { conhecimento da transmissão de VHB e VHC, estimar a } \\
\text { prevalencia sorológica destes vírus. }\end{array}$ & $\begin{array}{c}\text { - houve pouca adesão à recomendações de biossegurança, e pouco } \\
\text { conhecimento da transmissão microbiana e, } 8 \% \text { de prevalência para } \\
\text { hepatite B e } 2 \% \text { para hepatite C. }\end{array}$ & III \\
\hline
\end{tabular}




\section{DISCUSSÃO}

O aspecto cultural de se dar importância ao atributo da beleza, e a facilidade de acesso entre todas as camadas sociais para usufruir de serviços voltados para cuidados da aparência física em compasso com os padrões de estética corporal atuais, é uma realidade em todo mundo. Tal comportamento se reflete na economia, no crescimento da indústria de perfumaria e cosméticos e, sobretudo nos serviços para o embelezamento, cuja prerrogativa é a da beleza pessoal como uma apresentação de maior impacto(2).

No tocante aos profissionais que desempenham as atividades no segmento de beleza e estética, constatouse uma baixa escolaridade, apesar do crescimento do setor. Possivelmente tal fato se deva à origem das profissões, ao seu não reconhecimento formal em muitos países e, com isso, a não exigência legal de qualquer formação técnica ou capacitação do profissional para exercer atividade, além da falta de orientação e acompanhamento das agências de saúde. Assim, pressupõe-se que muitos destes profissionais aprendem a atividade sob orientações de outros mais antigos, não adquirindo o conhecimento sobre os possíveis impactos à saúde humana do próprio profissional e do cliente, indispensável para sua atuação $0^{(2,5)}$.

Os profissionais que trabalham como cabeleireiros, manicures, pedicures e barbeiros nem sempre passam por cursos ou treinamentos que abordam recomendações de biossegurança. Esta falta de formação e/ou conhecimento é registrada na literatura evidenciando que os salões de beleza e clínicas de estética passam a contribuir na disseminação de micro organismos e doenças que muitas vezes são adquiridas, mas que acabam não sendo associadas a estes ambientes, num processo de transmissão silenciosa ${ }^{(6,9,12)}$.

Muitos são os micro organismos que podem ser transmitidos e disseminados por serviços de beleza ${ }^{(4,9,17)}$. Eles possuem como vias de entrada mais eficientes no organismo humano a pele e mucosas com abrasões ou feridas.

Embora a hepatite B seja transmitida principalmente pela via sexual e pelo uso de agulhas contaminadas, há, entretanto, a notificação de casos sem qualquer associação com tais vias, inferindo que outras formas de transmissão sejam relevantes ${ }^{(4,11,14)}$. Vale lembrar que o
VHB apresenta certa resistência no meio ambiente, podendo sobreviver por uma semana em amostra de sangue seco sobre alguma superfície ${ }^{(18)}$. A disseminação do vírus por atividades de cabeleireiro, podólogo, barbeiro e manicures tem sido atribuída, provavelmente, como resultado de lesões por materiais perfurocortantes que deveriam ser de uso único ou que não foram submetidos a processos de esterilização adequados ${ }^{(6,11,14-15)}$.

Outro ponto de discussão nas prováveis vias de transmissão ocupacional de hepatites $B$ e $C$ no segmento de beleza e estética é a posição de manicures e pedicures em negar que causam injúrias nos tecidos dos clientes com possível sangramento. Os próprios profissionais, contudo, confirmam que pequenos cortes ocorrem inadvertidamente, sendo que à medida que se tornam mais experientes estes acidentem são menos frequentes ${ }^{(4)}$. $O$ que não se pressupõe ser uma afirmativa confiável.

Quanto aos instrumentos, verificou-se que estes se mantém possivelmente contaminados, pois não são esterilizados e são utilizados em outros clientes e nas próprias manicures que, de forma geral, tratam de suas unhas com instrumentos usados no estabelecimento. $E$, neste contexto, as manicures podem se ferir e entrar em contato com micro organimos que poderiam ter sido eliminados por métodos de reprocessamento(2).

Em relação à conduta dos profissionais após o acidente com exposição a material biológico, verificou-se que estes não praticam qualquer medida preventiva. Evidenciou-se a grande preocupação em estancar o sangramento pelo uso de hemostasia química ou mecânica ${ }^{(2-4,8)}$. No entanto, na ocorrência de acidentes envolvendo material biológico, o protocolo preconizado pela Agência Nacional de Vigilância Sanitária (Anvisa) e pelo Centro para Controle e Prevenção de Doenças dos EUA (Center for Disease Control and Prevention - CDC) deveria ser seguido. Isto inclui a lavagem do local imediatamente com água corrente, a notificação do acidente e a execução de exames sorológicos para deteç̧ão do VHB, VHC e para o HIV em profissionais e cliente-fonte $^{(2,19)}$.

Quanto à imunoproteção para o VHB, é indicado que o profissional tenha recebido três doses da vacina específica, considerado como esquema completo. E para total surpresa, verificou-se que muitos profissionais do 
segmento da beleza e estética não receberam nenhuma dose da vacina, ou receberam uma ou duas sem completar todo o esquema vacinal de três doses ${ }^{(2,5,7)}$. 0 Ministério da Saúde brasileiro desde o ano de 2010 ampliou a abrangência incluindo manicures, pedicures e podólogos, independente da idade, no direito de receber a vacina contra hepatite $B$ gratuitamente ${ }^{(20)}$. Entretanto, ao que parece, estes profissionais ainda não estão sensibilizados para a importância de se vacinar.

Outro problema, abrangido pela literatura, foi a baixa adesão dos profissionais do segmento de beleza às recomendações de lavagem de mãos, uso de luvas, máscara, óculos, avental/capote e descarte adequado de material contaminado que devem ser aplicadas na prestação de cuidados a qualquer pessoa, quando há riscos ou na presença de sangue, secreções e excreções da pele e/ou mucosas ${ }^{(4-6,12,19)}$.

A indicação da lavagem de mãos deve acontecer na presença de sujidades visíveis nas mãos, antes e após o uso de luvas, após a utilização de instalações sanitárias e entre o atendimento a clientes ${ }^{(19)}$. Apesar de ter sido verificado que os profissionais da beleza e estética reconhecem a importância da lavagem das mãos como ato de higiene pessoal, não ficou evidente que estes a associam como medida de prevenção de infecção, não relatando lavá-las entre o atendimento de clientes ou antes de calçar as luvas. O fato de não lavar as mãos aumenta a possibilidade de transmitir e adquirir doenças e o uso de luva não elimina a necessidade de lavá-las. Sabe-se, contudo, que alguns detalhes influenciam na adesão à lavagem de mãos como a disponibilização de pias em locais de fácil acesso, próximo a área de trabalho, com dispenseres de sabão líquido e papel toalha, o que não foi identificado nos salões de beleza ${ }^{(2,19)}$. A adesão insatisfatória à lavagem de mãos é discutida no âmbito hospitalar entre profissionais de saúde e, sugere-se que a adesão não está diretamente associada ao conhecimento teórico, mas à incorporação desse conhecimento ao hábito, prática diária e sensibilização constante dos profissionais ${ }^{(21)}$.

O uso dos EPI protege profissionais e clientes da exposição a sangue, outros fluidos corpóreos e fragmentos de unhas que podem carrear micro organismos transmissíveis ${ }^{(19)}$. A adesão ao uso de luvas durante os procedimentos variou entre 5\%- $20 \%$ dos profissionais da beleza apesar dos mesmos avaliarem em
50-80\% a necessidade do uso de tal EPI para sua própria proteção ${ }^{(2,4)}$. As luvas previnem a contaminação grosseira das mãos e a transmissão cruzada de micro organismos entre profissionais e clientes. Elas devem ser retiradas e descartadas depois do uso, entre um cliente e outro, além de se evitar tocar itens não contaminados ou superfícies no ambiente ${ }^{(19)}$. No Brasil observou-se que $87,5 \%$ das manicures que apresentaram marcador sorológico positivo para hepatite $B$ não usavam luvas descartáveis durante execução de seus procedimentos (2).

Outro aspecto relevante e observado nas publicações analisadas foram as não conformidades quanto ao conhecimento da temática dos reprocessamentos. Fato revelado pela fragilidade na definição de conceitos (esterilização versus desinfecção), pela ausência de critérios na indicação dos instrumentais e materiais para os diferentes métodos de reprocessamento, uso de produtos químicos não padronizados e não reconhecidos ou indicados com a finalidade do uso observado. Ademais, houve relatos da ausência de limpeza prévia dos instrumentais ao processo de desinfecção/esterilização, uso de diferentes métodos com intenção de esterilização como luz Ultra Violeta, esferas de vidro aquecidas, álcool 90-99\%, querosene, estufa funcionando em diversas temperaturas e tempo de exposição(2-10,12-13,15-16).

De acordo com o CDC e Anvisa a classificação dos artigos por nível de contaminação deve ser o passo inicial em qualquer processo, para que na sequência seja realizada a sua descontaminação, seguido pela limpeza, enxágue em água, imersão em desinfetantes preconizados (glutaraldeído 2\%, hipoclorito de sódio 1\%, ácido peracético $0,2 \%$ ) ou esterilização por métodos físicos (autoclave) ou métodos químicos (glutaraldeído $2 \%$ ou ácido peracético $0,2 \%$ ) além do armazenamento adequado dos dispositivos já reprocessados(3,19). Verificou-se em um estudo que $100 \%$ das manicures abordadas, não controlavam o tempo e a temperatura no processo de esterilização, sendo que $92 \%$ não realizavam a limpeza prévia dos instrumentos e apenas $7 \%$ utilizavam materiais descartáveis ${ }^{(2)}$.

O método de esterilização por estufa é amplamente utilizado entre manicures e pedicures. No Brasil apenas $7,14 \%$ dos profissionais entrevistados conheciam o tempo de exposição ao agente esterilizante e a temperatura ideal de esterilização na estufa. Além disso, 
é bastante divulgado o uso de "forninhos", e não estufas do tipo forno de Pasteur, que não permitem o uso de termômetro externo. Outro problema é a prática habitual de abrir o equipamento antes do término do processo de esterilização(2-3).

A estufa (forno de Pasteur) possui restrições quanto ao uso no que se refere ao tempo de pré-aquecimento, exposição do material ao processo e cuidados especiais na sua retirada, evitando-se assim choques térmicos com possível recontaminação do material submetido a esterilização. Assim a utilização de autoclaves automáticas devem ser preferidas pelo fato de minimizarem as possibilidades de interferência no processo de esterilização, apesar disso verificou-se que seu uso foi minimamente encontrado (1\%-4\%) no Brasil e em outros países ${ }^{(2,4)}$. E, apesar de não constituir um método recomendado ou aprovado para esterilização pela ineficácia na destruição de micro organismos, inclusive do HIV, o uso de lâmpadas do tipo ultravioleta também foi registrado(3-4).

Possivelmente os achados destes estudos ainda apresentam limitações pela constatação de que os mesmos, apesar de proporem a identificação do conhecimento dos profissionais do segmento de beleza acerca das recomendações de biossegurança, não analisaram os mesmos itens entre si. Outros aspectos que merecem destaque se referem à notória influência entre as condutas adotadas, falta de conhecimento técnico identificado, insuficiente formação técnica, a não conformidade no uso de protocolos para exposição à material biológico pelos profissionais e sobretudo, pela ausência de vigilância deste setor pelos órgãos de vigilância sanitária, seja para ações de orientação, informação ou monitorização de sua ações ${ }^{(3-4,6,8)}$.

\section{CONCLUSÃO}

Os tratamentos de beleza executados principalmente por manicures, pedicures, cabeleireiros e barbeiros promovem a frequente contaminação de instrumentais e materiais por sangue e contato com pele íntegra, podendo constituir uma fonte para transmissão cruzada de micro organismos causadores de doenças de impacto social, como as hepatites e o HIV.

Em meio ao risco da disseminação microbiana, ações educativas podem e devem ser implantadas para ampliar o conhecimento dos profissionais a respeito das recomendações de biossegurança e do risco ocupacional, estimulando-os para adesão às práticas de biossegurança, de higienização e saúde ocupacional, levando-se em conta fatores sociais, econômicos e culturais.

Aspectos quanto ao desconhecimento e a baixa adesão às medidas de biossegurança foram encontrados como o descarte de perfurocortante no lixo comum, a baixa prática de lavagem de mãos, desconhecimento da necessidade de vacinação contra hepatite $B$, desconhecimento dos mecanismos de transmissão de hepatites e HIV, não indicação dos métodos de reprocessamentos e reutilizações de instrumentais, uso inadequado de EPI, bem como insuficientes condições sanitárias e físicas, permitindo contaminações e aumentando o risco de acidentes.

Dada a importância que os estabelecimentos de estética e beleza têm na sociedade, do risco da transmissão de patógenos específicos do sangue, da subnotificação de doenças de relevância epidemiológicas e de impacto na saúde pública, os resultados desta revisão reafirmam a importância de um olhar mais atento dos pesquisadores sobre o risco iminente desta área de atividade. Reforça também o incentivo a outras pesquisas sobre a saúde ocupacional dos profissionais do segmento e à saúde dos clientes, na identificação de acidentes com materiais perfurocortantes, de fatores intervenientes a adesão às recomendações de biossegurança e, também, estimular pesquisas para subsidiar políticas públicas para o setor da estética e beleza no contexto nacional e internacional.

\section{FINANCIAMENTO}

Fundação de Amparo à Pesquisa do Estado de Minas Gerais - FAPEMIG. Edital 03/2011 - Programa Pesquisador Mineiro - PPM V-00340-11

2. Gir E, Gessolo F. Conhecimentos sobre AIDS e alterações nas ações profissionais das manicures de Ribeirão Preto. Esc Enf USP. 1998;32(2):91-100.

\section{REFERÊNCIAS}

1. Oliveira ACDS, Focaccia R. Survey of hepatitis B and C infection control: procedures at manicure and pedicure facilities in São Paulo, Brazil. Braz J Infect Dis. 2010;14(5):502-7. 
3. Johnson IL, Dwyer JJM, Rusen ID, Shahin R, Yaffe B. Survey of Infection Control Procedures at Manicure and Pedicure

Establishments in North York. Can J Public Health. 2001;92(2):134-7.

4. Stetler CB, Brunell M, Giuliano KK, Morsi D,Prince L, Newell-Stokes $\mathrm{V}$. Evidence-based practice and the role of nursing ledership. J Nurs Adm. 1998; 28(7/8):45-53.

5. Zahraoui-mehadji M, Baakrim MZ, Laraqui S, Laraqui O, El kabouss $\mathrm{Y}$, Verger $\mathrm{C}$ et al. Risque infectieux lié au sang chez les coiffeursbarbiers traditionnels et leurs clients au Maroc. Cahiers Santé. 2004;14:211-6.

6. Amodio E, Di Benedetto MA, Gennaro L, Maida CM, Romano N. Knowledge, attitudes and risk of HIV, HBV and HCV infections in hairdressers of Palermo city (South Italy). The European Journal of Public Health. 2009;5:1-5.

7. Wazir MS, Mehmood S, Ahmed A, Jadoon HR. Awareness among barbers about health hazards associates with their profession. J Ayub Med Coll Abbottabad. 2008; 20(2):35-8.

8. Arulogun OS, Adesoro MO. Potential risk of HIV transmission in barbering practice among professional barbers in Ibadan, Nigeria. African Health Sciences. 2009;9(1):19-25.

9. Takwale A, Agarwal S, Holmes SC, Berth-Jones J. Tinea capitis in two elderly women: transmission at the hairdresser. $\mathrm{Br} \mathrm{J}$ dermatol. 2001;144:898-900.

10. Corrales CL, Sánchez CL, Tunjano JCO, Gómez CPL. Evaluación de la efectividad de los procesos de desinfección de los utensílios en salones de belleza en un municipio de Cundinamarca. NovaPublicación Cientifica. 2007;5(7):65-9.

11. Candan F, Alagozlu H, Poyraz O, Sumer H. Prevalence of hepatitis $B$ and $C$ virus infection in barbers in the Sivas region of Turkey. Occup Med. 2002;52:31-4.

12. Ruddy M, Cummins M, Drabu Y. Hospital hairdresser as a potential source of cross-infection with MRSA. J Hosp Infect. 2001;49:225-7.

13. Winthrop KL, Abrams M, Yakrus M, Schwartz I, Ely J, Gillies D et al. An Outbreak of Mycobacterial furunculosis Associated with Footbaths at a Nail Salon. N Engl J Med. 2002;346(18):1366-71. 14. Mariano A, Mele A, Tosti ME, Parlato A, Gallo G, Ragni P et al. Role of Beauty Treatment in the Spread of Parenterally Transmitted Hepatitis Viruses in Italy. J Med Virol. 2004;74:216-20.

15. De Schrijver K, Maes I, Van Damme P, Tersago J, Moës E, Van Ranst M. An Outbreak of Nosocomial Hepatitis B virus Infection in a Nursing Home for the Elderly in Antwerp (Belgium). Acta Clin Belg. 2005;60-2.

16.Huijsdens XW, Janssen M, Renders NHM, Leenders A, Van Wijk P, Van Santen-Verheuvel MAG, Van-Driel JK, Morroy G. MethicillinResistant Staphylococcus aureus in a Beauty Salon, the Netherlands. Emerg Infect Dis. 2008;14(11):1797-99.

17. Redbord KP, Shearer DA, Gloster H, Younger B, Connelly BL, Kindel SE et al. Atypical Mycobacterium furunculosis occurring after pedicures. J Am Acad Dermatol. 2006; 54(3):520-4.

18. Adeleye IA, Osidipe OO. Isolation and Characterization of Microorganisms from Instruments used by Pedicurists Operanting within Lagos Metropolis, Nigeria. West Indian Med J.

2004;53(6):413-5.

19. Siegel JD, Rhinehart E, Jackson M, Chiarello L. Healthcare Infection Control Practices Advisory Committee. Guideline for Isolation Precautions: Preventing Transmission of Infectious Agents in Healthcare Settings. Center for Disease Control and Prevention (CDC) 2007 Jun 219p. [cited 2010 set 04]. Available from:

http://www.cdc.gov/hicpac/2007ip/2007isolationprecautions.html 20. Brasil: Ministério da Saúde; Departamento de DST-AIDS.

Hepatites Virais. Notícias do Departamento de DST, Aids e Hepatites Virais. SUS amplia oferta de vacina contra a hepatite B no Brasil [cited 2010 mar 20]. Available from:

http://www.aids.gov.br/node/40143 21. Primo MGB, Ribeiro LCM, Figueiredo LFS, Sirico SCA, Souza MA. Adesão à prática de higienização das mãos por profissionais de saúde de um Hospital Universitário. Rev. Eletr. Enf. [Internet]. 2010 [cited 2012 sep 30];12(2):266-71. Available from: http://www.fen.ufg.br/revista/v12/n2/v12n2a06.htm.
Artigo recebido em 14/07/2011. Aprovado para publicação em 26/01/2012. Artigo publicado em 30/09/2012. 